\title{
Intergenerational Support
}

\section{Psychological and Cultural Analyses of Korean and German Women}

\author{
Beate Schwarz, Gisela Trommsdorff, Uichol Kim and \\ Young-shin Park \\ University of Basle, Switzerland, University of Konstanz, Germany, \\ Inha University, South Korea and Inha University, South Korea
}

\begin{abstract}
In this study, adult daughters from an East Asian culture (South Korea: $N=398$ ) and a western culture (Germany: $N=313$ ) were compared with respect to the extent and the direction of intergenerational support, the associations between value orientations, relationship quality and intergenerational support, and with respect to the meaning of perceived reciprocity within these processes. Results showed a more extensive exchange of support in the Korean as compared to the German sample and very similar associations between values and relationship quality with support to parents in both cultures. However, in the German sample a negative association between adult daughters' perception of giving more than receiving and the quality of the relationship was indicated. The results are discussed in light of the Confucian concept of filial piety and the western theoretical model of intergenerational solidarity.
\end{abstract}

keywords: Germany $\downarrow$ intergenerational support $\downarrow$ South Korea

Most industrialized countries are facing dramatic demographic changes, one of which is increasing life expectancy. At present, the average life expectancy in Korea is 79.3 years for women and 71.8 years for men. In Germany, the average life expectancies are slightly higher: 81.2 years for women and 75.2 years for men (United Nations Population Division, 2004). The increased life expectancy affects the family structure and dynamics since the length of the lifetime that parents and their children share has never before been so long (Lauterbach, 1995; Uhlenberg, 1995). These changes have brought the adult parent-child relationship into the focus of research in recent years.

Support exchange is a central issue in intergenerational relationships. Irrespective of the existence of a social security system, the exchange of 
support remains important in the parent-child relationship throughout their whole life. This intergenerational exchange is comprised of emotional, instrumental and financial support. The amount, type and meaning of exchange for the parent-child relationship in adulthood have not been fully investigated in East Asian countries and even less so in cross-cultural comparisons (see Trommsdorff, in press a, in press b).

The general goal of the present study was to compare two countries that differ significantly in their cultural backgrounds and specific cultural concepts with respect to intergenerational relationships: South Korea and Germany. We assumed that the different cultural concepts affect the meaning of individual values and norms and relationship quality for the intergenerational exchange of support as well as the meaning of reciprocity in this exchange. Thus, one aim was to investigate culture-specific associations between individual norms and values, the quality of the relationship with the parents and the support adult daughters provide to their parents. The primary goal of the study was to explore the different meanings of balance and imbalance (i.e. lack of reciprocity) in the exchange of intergenerational support for the relationship. The norm of reciprocity seems to be valid in both cultures, but the ways in which this norm is fulfilled may differ. However, this assumption has never been explored.

Korea is a relational and collectivist culture with a strong Confucian and Buddhist influence, while Germany is influenced by Christian values and, compared to Korea, is a more individualistic culture (Hofstede, 2001). The Confucian ethical system provides clear definitions of the roles and duties in the parent-child relationship across the lifetime; the Confucian concept of filial piety particularly refers to the role of the eldest son. Confucianism and the demands of filial piety are still influential in Korea (Sung, 1998). In Germany, no such indigenous concept of the parent-child relationship exists. However, in western cultures the model of family solidarity serves as a valuable description of the adult parent-child relationship.

\section{Intergenerational Relations and Support in Korea}

Confucianism has influenced all facets of Korean society. The basis of self, relationships and society is considered to be the family. In Korea, relationships, not individuals, are considered to be a basic unit. In contrast to the western emphasis on individuality and uniqueness, the Korean worldview focuses on emotions that bind individuals and family members together. For example, the Korean word for human being is ingan (translated literally it means 'human between'). The human essence is basically relational and can be defined in terms of what happens between individuals. The family members are connected through mutual interdependence. Each 
family member defines him- or herself according to their relatedness to the other family members (Kim and Park, 2000; Markus and Kitayama, 1991).

Although Confucius considered the father-son relationship to be primary, it is the relationship between the husband and wife that is fundamental. Through the union of husband and wife children are born and the family lineage is maintained. The role of each family member is clearly prescribed; in the concept of filial piety the role of the eldest son is particularly well defined. Consistent with Confucian philosophy, a father and a mother have different roles. A mother represents the inner world of the child and the father represents the outside world (Kim and Park, 2000). Their contrasting roles are summarized by a common saying: 'a strict father, a benevolent mother'.

One of the prime responsibilities of a husband is to have a son who can continue the family line. The other main responsibility is to educate his son so that he will carry on the family name and represent the family. A mother, on the other hand, is responsible for raising children, ensuring that children respect and obey their father, taking care of elderly parents and relatives and managing household affairs and social relationships. The father's role is the symbolic head of the family. Thus, rights and obligations in Confucianism are role attached, unequal, relational and situational (Kim, 1994). The major obligation of children is obedience and respect. Even though in Confucianism the parent-child relationship is characterized as hierarchical, mutual positive affection is also an important aspect of the relationship (Hwang, 1999; Sung, 1995).

Support and caring are not a unilateral process. As children mature, they need to reciprocate the unconditional support provided to them. Based on the concept of filial piety, Kim and Choi (1994) listed the obligations that children have to fulfil. First, the children must respect their parents' opinions and authority. This respect has to be expressed through their daily behaviour (obeying). Second, the children must take care of the needs of their parents (attending). Third, they have to fulfil the materialistic needs of their parents (supporting). Fourth, they are obliged to provide solace and reassurance to the parents (comforting). Finally, even after their parents pass away, children are encouraged to honour their parents' achievement, pursue their intentions, complete their undertakings and sustain their social network (honouring).

In Korea, the conceptions of past and future are not abstract ideas, but are relationally based. Even in modern Korea, people pay respect to their ancestors by bowing to them at their grave and symbolically sharing a meal with them. Grandparents are respected as a living testimony and link to the past. Children, on the other hand, represent the future of the family and as such great emotional, financial and social investments are made for them and in them. 
Reciprocity plays a major role in the concept of filial piety. The adult children are obliged to pay back what the parents have done for them (Sung, 1995). Reviews of Korean parent-child relationships reveal that children feel indebted to their parents for the sacrifice they made for them (Kim and Park, 2005; Park et al., 2002). For adult children in Korea, one of the most important reasons for parental care is to repay debts to their parents (Sung, 1995). However, children need not reciprocate in kind, but show their appreciation by doing their best in their endeavours. When they are students, they study hard and try to succeed academically. Empirical studies in Korea have shown that a sense of indebtedness to parents increases students' achievement motivation, which in turn functions to increase the amount of time they dedicate to their studies (Park and Kim, 2004). As young adults, children try their best to succeed economically, socially and to have a harmonious family of their own. They are expected to show their appreciation to their parents by supporting them when they are old, but also to make sacrifices for their children as their parents have done for them.

Confucian family values and the concept of filial piety have been transformed in the modern era. With modernization, urbanization and industrialization, the nuclear family structure has replaced the traditional extended family. Currently, fewer than 10 percent of families have three generations living under one roof. In 1975, the average size of a household was more than five, but this number was reduced to three in 2000 (Korean National Statistics Bureau, 2001). Even in rural areas, the family size is relatively small. Sex-role discrimination has diminished significantly in the family, in schools and, to a lesser extent, in the workplace. In 1965, 37 percent of women participated in the workforce. Although the economy has expanded approximately 100 -fold since 1965, only 47 percent of women participated in the workforce in 2000 (Korean National Statistics Bureau, 2001).

Parental roles within the family have changed as well, particularly for fathers. Today's fathers report more nurturance and warmth towards their children than grandfathers report retrospectively (Jung and Honig, 2000). Nevertheless, the father is still the head of the household, representing the family, and the mother is responsible for raising and educating the children. Although the traditional family structure and values have changed with modernization, two important features of the socialization practice still remain: parental devotion and indulgence. In Korea, parents view unselfish devotion and sacrifice to their children as their basic role and duty. The obligations of adult children as prescribed in the concept of filial piety have undergone some modifications as well but they are still important in everyday life (Sung, 1998).

Based on the concept of filial piety, Korean family law stipulates that 
children have to support their parents when they are old - although it is inconceivable that one would choose not to support one's parents. The government provides a small pension only if the elderly cannot be supported by their children (i.e. they do not have any children or their children are unable to support them financially). Fewer than 3 percent of the elderly population receives this small pension from the government (Korean Ministry of Public Welfare, 2002). According to a study conducted by Won (2002), nearly half of the elderly are supported by the eldest son's family (47 percent), 20 percent by other sons' families, 16 percent by daughters' families and 7 percent by unmarried children. In a national survey, 69 percent of parents aged 65 years and older received financial support from their children (Chung et al., 1998).

In addition, the Korean government provides only partial health care support (around 70 percent of the total cost and it excludes serious illnesses such as cancer or stroke). It is the responsibility of the children to cover the remaining costs. Won (2002) has found that for serious illnesses, it is the spouse who provides the necessary support (44 percent), followed by the eldest son's family members (23 percent), members of other sons' families (14 percent), the members of daughters' families (10 percent) and other family members (3 percent). In terms of emotional support for the elderly, very similar patterns of responsibilities were found.

When Chung et al. (1998) asked respondents from a national sample who is responsible for taking care of their elderly, 47 percent reported that it is the responsibility of the eldest son, followed by the children who are able to support them (28 percent), the elderly themselves (16 percent), other sons (7 percent) and daughters (1 percent). In a study conducted by Kim et al. (2000), respondents reported that the elderly are more likely to receive financial and emotional support from their children than to provide support to their children. This is likely the case because the elderly grew up during a time when Korea was underdeveloped and they had to maintain a subsistence level and had no resources to save up for old age. Their children, however, grew up during a time of rapid economic growth. They have greater resources and time to support their parents financially and emotionally.

With respect to reciprocity in intergenerational exchange, Kim and Kim (2000) found that although children are likely to provide more financial and emotional support to parents than they received in turn, this imbalance is gradually decreasing due to the increasing affluence of the elderly population. They also found that those elderly who are able to provide greater support to their children were more satisfied with their life in general. Those elderly who reported unilateral support (i.e. that they only gave support or they only received support) were less satisfied, and those 
who neither gave nor received support from their children reported the lowest life satisfaction. Thus, these findings underline the importance of reciprocity in intergenerational relationships in Korea. According to Lee (2002), a balanced exchange of emotional support is more likely among those elderly with a higher socioeconomic status.

As to the quality of the relationship, Hong (1998) found that those respondents with a higher exchange of financial support showed more affection for their children and at the same time experienced greater conflicts with them. In other words, financial exchange can be a doubleedged sword. Such a pattern was not observed for practical exchange.

To summarize, according to Confucian ideas, a strong interdependent orientation of family members, close emotional ties and high filial obligations characterize the adult parent-child relationships. The adult children's obligation is to support ageing parents not only financially but also instrumentally and emotionally. The norm of reciprocity applies to support between adult children and their parents. However, according to Confucian belief, adult children can pay their debts to their parents in part by investing in the next generation.

\section{Intergenerational Relations and Support in Germany}

For Germany, no indigenous concept describing the parent-child relationship, like filial piety, exists. Instead, the model of intergenerational solidarity of Bengtson and colleagues (e.g. Bengtson and Roberts, 1991) has served as the theoretical background of studies on the adult parent-child relationships in western cultures. The authors proposed a model consisting of a pattern of positive associations between five aspects of solidarity, which together influence the frequency and quality of intergenerational contact.

The opportunity structure of family interaction (e.g. geographic proximity of parents and children, secure financial situation) and the norms of family obligations are basic prerequisites for the intergenerational exchange of support and the maintenance of emotional quality in the relationship between parents and children. According to the model of intergenerational solidarity, the quality of the relationship influences the support exchange and, in turn, the reciprocity of this exchange (or lack of it) affects the quality of the relationship. A balance between the help given to and received from a parent should increase the positive emotions between parents and adult children and the quality of their relationship. An imbalance should have just the opposite effect. While most assumptions derived from the model have been investigated intensively, until now the association between reciprocity in support exchange and relationship quality has been explored in only a few studies (e.g. Silverstein et al., 2002). 
The norm of reciprocity is important in social relationships in western cultures. According to this norm, the stability of social relationships is based on the expectation that the help and support given to another person will be reciprocated in an adequate time period and in a contingent manner (Gouldner, 1960). With respect to family relationships, reciprocity may be a less important factor influencing the relationship stability than in other social relations, such as friendship relations. More specifically, reciprocity among family members may not be established with the same kind of support and can be accumulated over the life course in terms of 'support banks' (Antonucci, 1985). Nevertheless, there is empirical evidence for the expectation that the norm of reciprocity applies to family relationships as well (for a review, see Schwarz, in press).

In accordance with the model of intergenerational solidarity, the relationship between adults and their parents in Germany is often described as close and harmonious with intensive exchange of support on the basis of frequent contact. Representative statistics of Germany highlight the fact that parents and children live in close proximity even when the children become adults. According to the Ageing Survey (Szydlik, 2000), more than 80 percent of middle-aged and older children live within two hours of their parents, and almost 50 percent live in the same city or district. More than a third have daily contact with their parents and nearly another third have contact with their parents several times a week (Szydlik, 2000). Only a small minority of adult children have little or no contact at all with their parents ( 3 percent contact their parents a few times a year and 2 percent have no contact at all; Szydlik, 2002).

Frequent contact between the generations is the norm and the exchange of support is continuous. For the greater part of life, more support flows from parents to their children than vice versa, even in adulthood; this is especially true for financial support. Since the German old-age security system provides a full pension for all former employed persons and a share for their partners, they are likely to be financially independent. As a result of governmental support, most children are not obliged to support their elderly parents. However, many parents have an income large enough to help their children if they are in need. In Germany in 1996, 30 percent of 55- to 69-year-old parents and 24 percent of 70- to 85-year-old parents provided financial support to their adult children, but only 2-3 percent received financial support from their children (Kohli and Künemund, 2001).

Beyond financial support, the exchange of instrumental support, such as help in the household, is more often balanced between parents and children; in some cases, the children give more than they receive (Kohli and Künemund, 2001). ${ }^{1}$ These results point to the importance of the family as a major source of social support in Germany. This is also shown by the 
fact that, in the majority of cases, care for old and frail persons in Germany is provided by family members (husband, wife, daughters and daughters-in-law) (BMFSFJ, 2003). With respect to the quality of the adult parent-child relationship, several studies have described the relationship as warm and close (Buhl, 2000; Schwarz et al., 2005), conflicts seem to be rare (Schneewind and Ruppert, 1995).

The majority of adult children, middle-aged parents and elderly grandparents experience a balance of give and take with respect to instrumental help as well as communication (Alt, 1994). Additionally, most adult daughters perceive reciprocity in the overall exchange of emotional and instrumental support with their parents (Schwarz, in press). Besides strong norms of filial obligations, adult children also report strong norms of reciprocity in family relationships (Szydlik, 2000). Imbalance in the exchange of support seems to affect the relationship between adult children and parents negatively (Levitt and Guacci, 1992; Rook, 1987), particularly when adult children feel that they give more than they receive (Schwarz, in press).

To summarize, filial obligations and a high emotional quality are important aspects in the adult parent-child relationships in Korea as well as in Germany. Each kind of support (emotional, instrumental, financial) is extensively exchanged between the generations. However, due to the comprehensive old-age security system in Germany there is almost no need for financial support of old parents by adult children as in Korea. On the contrary, it is the parents who support their adult children, particularly when they are in need. Reciprocity in the exchange of support seems to be important for a good parent-child relationship in adulthood. Unlike in Korea, in Germany it does not seem appropriate to establish a balance by investing in one's own children.

\section{Research Questions}

The present study had two main goals. First, we investigated if support provided by adult daughters to their parents is related to the daughters' values and norms and their perception of the relationship. Second, we investigated whether the perception of a lack of reciprocity is associated with a more negative view of the parent-child relationship. Comparisons were made between the associational patterns found for Korean and German women.

The concept of filial piety and the model of intergenerational solidarity refer to the importance of filial obligations and the emotional quality of the relationship between adult children and their parents. We expected that both affect the amount of support daughters give to their parents. Since filial piety also stresses interdependence in the relationship, the 
interdependent orientation of the daughters was also considered as a predictor. However, the perspective on values and norms should be extended to the values of individualism and collectivism. Since the seminal work of Hofstede $(1980,2001)$, both dimensions have proven useful in cross-cultural research. ${ }^{2}$

With respect to the emotional quality of the relationship, two positive aspects (intimacy and admiration) as well as a negative aspect (conflicts) were considered. Our hypotheses were: individualism would be negatively related to the frequency of support given to the parents, while collectivism, interdependence and high expectations of filial obligations would be positively related. Intimacy and admiration in the relationship with the parents were also expected to be positively related to support given. Additionally, based on the findings of Hong (1998), we hypothesized a positive relation between parent-child conflict and support.

In both Korea and Germany, strong norms of filial obligations prevail. However, the obligations and the interdependence between family members are higher in Korea. Thus, we expected norms and values would be more strongly related to support given by the daughter in the Korean sample. Since emotional ties and the quality of the relationship are important in both cultures, we did not expect cultural differences in the association between the relationship quality and the support given by the daughter.

As previously described, the norm of reciprocity is valid in intergenerational relationships in both cultures. However, while Korean adult children can establish reciprocity not only by supporting their parents but also by investing in their own children, Germans are more obliged to pay back their debts directly to the parents. Thus, we assumed that the German daughters would feel more pressure to establish reciprocity, which would then influence their subjective perception of reciprocity. We hypothesized that the Korean adult daughters would perceive less balance and more imbalance than the German daughters. Furthermore, we expected perceived reciprocity to be of less importance for Korean daughters' than for German daughters' quality of relationships with their parents. Thus, we hypothesized weaker associations between perceived reciprocity and the relationship quality for Korean women as compared to German women.

\section{Method}

\section{Procedure}

This study is part of the cross-cultural Value of Children and Intergenerational Relations Study (see Trommsdorff, 2001; Trommsdorff and Nauck, 2005). The procedures of recruitment and assessment differed in the two 
countries. A convenient sampling method was used in Korea. Samples were recruited in and around the city of Incheon, near Seoul. Respondents were recruited by contacting the mothers of middle school students, and asking them to fill in a structured questionnaire.

The German sample was recruited through residents' registration offices from three different locations: a middle-sized university town in eastern Germany (Chemnitz), a middle-sized university town in southern Germany (Konstanz) and a large city from an urbanized industrialized region in northwestern Germany (Essen). Trained female interviewers carried out the standardized face-to-face interviews individually with each respondent. Each interviewee answered all the questions in the assigned sequence. A small gift was presented at the end of the interview.

\section{Participants}

The present study is based on a sample of women with at least one parent still alive (Korea: $N=398$, Germany: $N=313$ ). Furthermore, women who did not live with a partner were excluded because some studies point to differences in intergenerational support between single and married women. Analyses are based on a total of 305 women from Korea and 264 women from Germany (in the following we refer to these women as adult daughters). In the Korean sample, in 45 percent of the cases both parents were still alive, in 49 percent of the cases the father had died and in 6 percent of the cases the mother had died; the respective percentages for the German sample were 58 percent, 35 percent and 7 percent.

The samples from Korea and Germany differed with respect to some sociodemographic characteristics. The Korean women were significantly younger than the German women $(M=41.55$ vs $42.97 ; t[455.96]=4.32$, $p<.001)$. The same was true for their elderly mothers $(M=67.91$ vs 69.99 ; $t[472.47]=2.80, p<.01)$ while their fathers did not differ significantly in age.

The geographical distance between the women and their parents differed remarkably between the Korean and German sample. The percentages of Korean women living in the same household with their fathers or mothers was higher than among the German women, but more German women lived close to their parents (distance to father: $\chi^{2}[4, N=284]=$ 29.99, $p>.001$; distance to mother: $\chi^{2}[4, N=470]=52.63, p>.001$ ). Given the greater geographical distance, it was not surprising that the frequency of contact between the women and their parents was lower in the Korean than in the German sample (contact with mothers: $\chi^{2}[2, N=471]=42.39$, $p>.001$; contact with fathers: $\left.\chi^{2}[2, N=284]=7.79, p>.05\right)$.

Compared to national statistics, both the Korean and German samples were biased towards higher education. The Korean women's employment 
rate was lower than the national average, the Germans' comparable with national average. The figures with regard to geographical distance are in accordance with national statistics in both countries.

\section{Measures}

Self-reports of the adult daughters were assessed for the variables described in the following. Two variables were included as control variables: distance between daughters' and parents' residence, and parents' age. It was expected that residential distance (indicated on a scale from 1 $=$ 'in your home' to $5=$ 'abroad') affects at least the provision of instrumental support, while parents' age was used as a proxy of parents' need of support.

Four indicators representing individual norms and values were utilized in the study. The items of all indicators of values and norms were rated on a five-point Likert-type scale ranging from 1 to 5 with high values indicating high agreement.

Collectivism and Individualism. A short version of the Schwartz instrument (Schwartz and Bilsky, 1990) that was developed as part of the Colindex (Chan, 1994) was used to assess the general values of the daughters. Seven items referring to individualism and six items referring to collectivism reached satisfying reliabilities: Cronbach's alphas in the Korean sample were .74 for individualism and .78 for collectivism; the respective internal consistencies in the German sample were .70 and .75.

Interdependent Self. To assess the interdependence of the daughters, a short version of Singelis's (1994) Self-Construal Scale was used. After modification of the wording, the items referred to the respondent's family (e.g. 'It is important to me to respect decisions made by my family'). The reliability of this five-item scale was $\alpha=.71$ for the Korean women and $\alpha=.74$ for the German women.

Expectations of a Grown-Up Child. This measure assessed the filial obligation of the daughters. Based on an open question from the original Value of Children Study (Arnold et al., 1975), a standardized instrument was developed. The instrument consists of 14 items assessing expectations of a grown-up daughter and of a grown-up son. The internal consistencies were high (Korea: $\alpha=.92$; Germany: $\alpha=.88$ ).

Relationship Quality. Three indicators of quality of relationship with mother and father were used. They were adopted from the Network of Relationships Inventory (NRI) (Furman and Buhrmester, 1985): intimacy (e.g. 'How often do you tell your mother/father everything that is on your 
mind?') (reliabilities were, in Korea: .78 and .84 for mothers and fathers respectively; Germany: .85 and .78) and admiration (e.g. 'How often does your mother/father let you know that you are good at many things?') (Korea: $\alpha=.72$ for mothers, .70 for fathers; Germany: .87 and .85). The third scale assessed conflict between the adult daughter and her parents (e.g. 'How often do you and your mother/father disagree and quarrel?'). The reliabilities were satisfactory (Korea: .77 for both parents; Germany: .85 for mothers, .77 for fathers). The respondents rated three items each of intimacy, admiration and conflict on a five-point scale $(1=$ 'never' to 5 = 'always') with separate assessments of the relationship with the mothers and fathers.

Social Support between Adult Daughters and their Parents. Both adult daughters' reports on help given to parents as well as help received from parents in the last 12 months were assessed. Three kinds of support were assessed: financial support (one item), instrumental and emotional support (each consisting of three items). Again, all items were rated on a five-point scale $(1=$ 'never' to $5=$ 'always'). This assessment of social support did not refer to perceived social support in the sense that daughters rated how likely they would be to receive help when they are in need. However, the ratings of frequency comprise subjective evaluations by the daughters. Internal consistencies were high to moderate for emotional and instrumental support given to parents (Korea: $\alpha=.60$ and $\alpha=.80$; Germany: $\alpha=.83$ and $\alpha=.81$ ) as well as for emotional support received from parents (Korea: $\alpha=.75$; Germany: $\alpha=.85$ ), but were not satisfying for instrumental support received from parents in the German sample (Korea: $\alpha=.82$; Germany: $\alpha=.53$ ).

Perceived Reciprocity. One question assessed adult daughters' perception of reciprocity between the help given and received on a five-point scale from $1=$ 'I get much more than I give' to $5=$ 'I give much more than I get' (Schwarz, in press), which was assessed as a judgement across all three subdimensions of social support. For further analyses, the scale values 1 and 2 were pooled to form the category 'daughter receives more', values 4 and 5 were pooled to form the category 'daughter gives more' and the scale value of 3 indicated the category 'reciprocity' as it represented the middle point of balanced support on the original five-point scale. The categorical indicator of perceived reciprocity was dummycoded with the reciprocity group as the reference group. The dummies indicated the comparison with the 'daughter receives more' group and with the 'daughter gives more' group, respectively. 


\section{Results}

\section{Preliminary Analyses}

$t$-Tests comparing Korean and German daughters revealed that the Korean adult daughters were less individualistic than the German women $(t[532.55]=6.61, p<.001)$ but they did not differ with respect to collectivism and interdependency. The Korean women reported higher expectations of adult children's obligations towards their parents $(t[444.84]=$ $-9.27, p<.001)$.

With regard to intimacy in the relationship with father and mother, the Korean women did not differ significantly from the German women. However, Korean adult daughters reported less conflict with their fathers $(t[319]=2.86, p<.01)$ and mothers $(t[480]=3.15, p<.01)$, and reported receiving less admiration from their fathers $(t[318.28]=4.75, p<.001)$ and mothers $(t[489.61]=7.32, p<.001)$ as compared to the German daughters.

Analyses of covariance were conducted to compare Korean and German women with respect to the frequency of support controlled for age of the parents and geographical distance. The Korean adult daughters reported providing less emotional support $(F[1,467]=9.30, p<.01)$ and more instrumental $(F[1,470]=10.17, p<.001)$ and financial support $(F[1,471]=355.92, p<.001)$ given to the parents than the German women . With regard to the support the adult daughters received from their parents, culture differences appeared again. Korean daughters perceived receiving more emotional $(F[1,468]=4.05, p<.05)$, instrumental $(F[1,468]$ $=44.58, p<.001)$ and financial support $(F[1,467]=9.83, p<.01)$ than the German adult daughters. In sum, the intergenerational exchange of support was more intensive in the Korean than in the German sample, with the exception of emotional support provided by the daughters.

\section{The Relation between Value Orientations, Relationship Quality and Exchange of Support}

Simultaneous regression analyses were run to predict the three kinds of support that were given to the parents by four indicators of adult daughters' values and three indicators of the relationship quality. All analyses were controlled for parents' age and geographical distance. Analyses were run separately for the indicators of the relationship with the mother and with the father. The results for the relationship with the mother are summarized in Table 1.

In the Korean sample, the regression analyses including quality of the relationship with the mother revealed no significant effects of daughters' value orientation on emotional support, except that daughters with high expectations of adult children tended to provide more emotional support. However, the greater the sense of individualism, the more frequently the 
Table 1 Multiple Regression Analyses Predicting Support Given to Parents with Values and Quality of the Relationship of Adult Daughters with their Mothers in Korea $(\mathrm{N}=181-5)$ and Germany $(\mathrm{N}=234-5)$

\begin{tabular}{|c|c|c|c|c|c|c|c|c|c|}
\hline \multirow[b]{3}{*}{ Korean daughters } & \multicolumn{9}{|c|}{ Support given to parents } \\
\hline & \multicolumn{3}{|c|}{ Emotional $^{a}$} & \multicolumn{3}{|c|}{ Instrumental $^{b}$} & \multicolumn{3}{|c|}{ Financial $^{c}$} \\
\hline & B & SE B & $\beta$ & B & SE B & $\beta$ & B & SE B & $\beta$ \\
\hline Geographical distance & -.01 & $.05-$ & -.02 & -.18 & $.06-$ & $-.20^{* *}$ & -.03 & .07 & -.03 \\
\hline Mother's age & .01 & .01 & $.19^{* *}$ & .00 & .01 & .05 & .00 & .01 & .00 \\
\hline \multicolumn{10}{|c|}{ Daughters' norms/values } \\
\hline Individualism & .06 & .09 & .05 & .23 & .11 & $.16^{*}$ & -.11 & .12 & -.07 \\
\hline Collectivism & -.08 & .09 & -.07 & -.31 & .11 & $-.22^{* *}$ & -.10 & .13 & -.06 \\
\hline Interdependence & .09 & .10 & .07 & .18 & .12 & .11 & .28 & .14 & $.16^{*}$ \\
\hline Expectations & .11 & .06 & $.12^{+}$ & .11 & .08 & .10 & .13 & .09 & .11 \\
\hline \multicolumn{10}{|l|}{ Relationship quality } \\
\hline Intimacy & .27 & .07 & $.30^{* *}$ & .21 & .09 & $.19^{*}$ & .16 & .10 & .13 \\
\hline Admiration & .01 & .07 & .01 & .14 & .09 & .13 & .09 & .10 & .07 \\
\hline \multirow[t]{3}{*}{ Conflict } & .19 & .07 & $.18^{*}$ & .11 & .09 & .08 & .28 & .10 & $.20^{* *}$ \\
\hline & \multicolumn{9}{|c|}{ Support given to parents } \\
\hline & \multicolumn{3}{|c|}{ Emotional $^{d}$} & \multicolumn{3}{|c|}{ Instrumental $^{e}$} & \multicolumn{3}{|c|}{ Financial $f$} \\
\hline German daughters & B & SE B & $\beta$ & B & SE B & $\beta$ & B & SE B & $\beta$ \\
\hline Geographical distance & .15 & .06 & $.16^{* *}$ & -.21 & $.07-$ & $-.19^{* *}$ & .02 & .02 & .06 \\
\hline Mother's age & .03 & .01 & $.20^{* *}$ & .05 & .01 & $.30^{* *}$ & .00 & .00 & .05 \\
\hline \multicolumn{10}{|c|}{ Daughters' norms/values } \\
\hline Individualism & .08 & .12 & .04 & -.01 & .14 & .00 & -.02 & .04 & -.03 \\
\hline Collectivism & .06 & .12 & .03 & .09 & .14 & .04 & .05 & .04 & .10 \\
\hline Interdependence & .15 & .11 & .09 & .28 & .13 & $.14^{*}$ & -.04 & .04 & -.07 \\
\hline Expectations & .24 & .09 & $.17^{* *}$ & .20 & .10 & $.12^{+}$ & .01 & .03 & .03 \\
\hline \multicolumn{10}{|l|}{ Relationship quality } \\
\hline Intimacy & .22 & .08 & $.22^{* *}$ & .06 & .09 & .06 & .03 & .03 & .08 \\
\hline Admiration & .11 & .08 & .11 & .16 & .09 & $.13^{+}$ & .01 & .03 & .03 \\
\hline Conflict & .05 & .08 & .04 & .05 & .09 & .04 & .02 & .03 & .05 \\
\hline
\end{tabular}

Notes: ${ }^{a} R^{2}=.19 ;{ }^{b} R^{2}=.20 ;{ }^{c} R^{2}=.12 ;{ }^{d} R^{2}=.20 ;{ }^{e} R^{2}=.23 ;{ }^{f} R^{2}=.02$.

${ }^{+} p \leq .10 ;{ }^{*} p \leq .05 ;{ }^{* *} p \leq .01$.

daughters provided instrumental support. The higher the daughters' collectivism, the less likely they were to offer instrumental support to their parents. This result is surprising and contrary to our expectation. Given the low negative bivariate correlation between collectivism and instrumental support $(r=-.07)$, a suppressing effect seems to underlie this result. When we introduced collectivism after the controls and without other indicators of family values and norms, collectivism was not significantly related to instrumental support given to parents. 
With respect to financial support, interdependence played a role: the more the daughters preferred an interdependent orientation, the more frequently they gave financial support. Additionally, the Korean daughters' perception of the relationship quality was important. High intimacy with the mother was related to more emotional and instrumental support given to the parents, and high conflict with the mother was related to more emotional and financial support to the parents.

In the German sample, high expectations of an adult child were positively related to emotional support given to parents and interdependence was positively related to instrumental support. Here, the positive effect of the expectations of an adult child reached a trend level of significance. No other effects of value orientations and norms were found. With regard to relationship quality, only one significant result and one trend were found. The higher the intimacy with their mothers, the more daughters gave emotional support; daughters who perceived high admiration from mothers tended to provide more instrumental support to parents.

In the regression analyses including quality of relationship with father, we had significantly reduced sample sizes since many fathers were deceased. Thus, we decided to reduce the number of predictors by excluding the indicators of family values and norms (individualism, collectivism, interdependence and expectations of adult children) because the effects of the values and norms for the reduced sample would not be comparable with the larger sample and the number of predictors now fitted better to the small sample from Korea.

In the Korean sample, daughters who reported high intimacy with the father and high admiration from him tended to provide more emotional support (intimacy: $\beta=.21, p<.10$; admiration: $\beta=.20, p<.10$ ). However, conflicts with the fathers were also positively related to emotional support $(\beta=.24, p<.05)$. The perceived admiration from fathers and conflicts with them were both positively related to instrumental (admiration: $\beta=.26$, $p<.05$; conflict: $\beta=.24, p<.05$ ) and financial support (admiration: $\beta=$ $.20, p<.10$; conflict: $\beta=.31, p<.01$ ). For the German sample, intimacy with father was positively related to emotional support $(\beta=.28, p<.01)$ and, only at trend level, with instrumental support $(\beta=.16, p<.10)$. Additionally, conflicts between daughters and fathers were positively and significantly related to instrumental support $(\beta=.19, p<.01)$.

To test whether the observed differences between the results of the Korean and the German samples were significant, regression analyses were conducted for the whole sample including interaction terms between culture and the indicators of values and relationship quality. The continuous indicators were centred before the multiplication with culture (Aiken and West, 1991).

In the regression analyses including indicators of relationship with the 
mother, the two samples did not differ in the prediction of emotional support. With regard to instrumental support, the effect of collectivism was stronger in the Korean sample (interaction culture $\times$ collectivism: $\beta$ $=-.17, p<.05)$. Furthermore, the effects of interdependence and conflict with mother were again significantly stronger in the Korean than in the German sample (interaction culture $\times$ interdependence: $\beta=.13, p<.05$, culture $\times$ conflict: $\beta=-.13, p<.01$ ). With respect to indicators of the relationship with the father only a culture difference significant at the 10 percent level occurred for emotional support predicted by conflict (interaction culture $x \times$ conflict: $\beta=.13, p<.10$ ). The effect in Korea tended to be stronger. The effect of admiration from father on financial support was significantly stronger in the Korean sample (interaction culture $\times$ admiration: $\beta=.15, p<.05)$, the same was true for the effects of conflict on financial support (interaction culture conflict: $\beta=.23, p<.001$ ).

In sum, the patterns of relations of value orientation and relationship quality with support given to parents were very similar in the Korean and German sample. All differences that occurred were based on stronger relations in the Korean as compared to the German sample. This pattern was true for effects of value indicators and relationship indicators.

\section{Culture-Specific Meaning of Reciprocity}

A cross-tabulation compared the frequencies of the three categories of perceived reciprocity for Korean and German daughters. The Korean daughters more often reported an imbalance of support exchange in both directions $\left(\chi^{2}[2, N=522]=140.66, p<.001\right)$. A total of 42 percent of the Korean but only 16 percent of the German daughters felt that they received more than they gave, while 37 percent of the Korean daughters reported that they gave more than they received, compared to 12 percent of the German daughters. Consequently, the reciprocity category was more pronounced in the German sample: 21 percent of the Koreans but 72 percent of the Germans reported balanced support.

However, given the frequencies of support this result is surprising. There, across all three kinds of support, the exchange of the Koreans seemed to be more balanced than the exchange of the Germans. Multinomial logistic regressions were conducted to test how the report on frequency of social support (here the difference between support given and received for the three kinds of support separately) was related to the subjective perception of reciprocity and whether these relations differ for Korean and German women.

The three difference scores of support given and received did not predict whether Korean adult daughters felt they received more or gave more instead of a feeling of balanced support. For German women, the more their instrumental support to parents exceeded the support from 
parents, the less likely the daughters were to belong to the 'daughter receives more' group $(b=-1.11$, Wald $=13.87, p<.01)$. The more their emotional, instrumental and financial support to the parents exceeded the support from the parents, the higher the likelihood that the daughters belonged to the 'daughter gives more' group (emotional: $b=.92$, Wald $=$ $11.83, p<.01$; instrumental: $b=.42$, Wald $=4.59, p<.05$; financial: $b=.81$, Wald $=4.62, p<.05$ ).

In a second set of analyses, the culture-specific associations between perceived reciprocity and relationship quality were investigated with regression analyses. As predicted, Korean women's perceived (lack of) reciprocity had no significant effect on the quality of the relationship with the mother. Only daughters who perceived that they received more than they gave tended to report lower intimacy with the mother compared to daughters who perceived balance in support exchange (see Table 2).

In the German sample, the daughters' perception of giving more than they received was significantly related to reports on less intimacy with and admiration from the mother and more conflicts with her (see Table 2). To compare the results of the Korean and German women, regression analyses including interaction terms of culture and the reciprocity dummies were conducted with the total sample. The effect of the 'daughter gives more' dummy on admiration and conflict in the relation with the mother was significantly higher in the German as compared to

Table 2 Multiple Regression Analyses Predicting Quality of Relationship with Mother by Perceived Reciprocity of Korean $(\mathrm{N}=244)$ and German $(\mathrm{N}=243)$ Adult Daughters

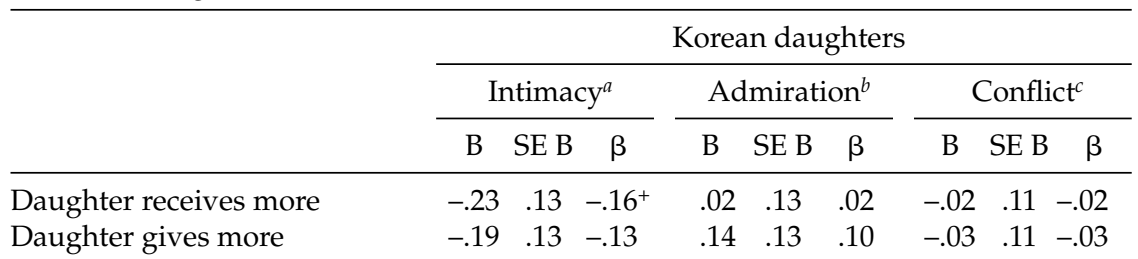

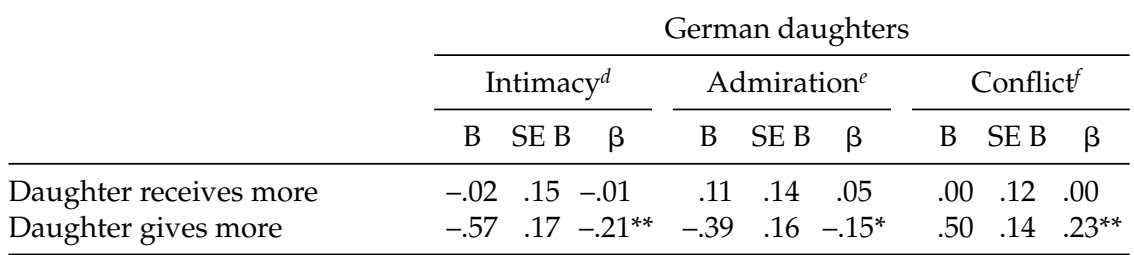

Notes: The independent variables are dummy-coded; both are contrasted with the category balanced support.

${ }^{a} R^{2}=.01 ;{ }^{b} R^{2}=.01 ;{ }^{c} R^{2}=.00 ;{ }^{d} R^{2}=.04 ;{ }^{e} R^{2}=.03 ; f R^{2}=.05$.

${ }^{+} p \leq .10 ;{ }^{*} p \leq .05 ;{ }^{* *} p<.01$. 
the Korean sample (admiration: $\beta=.26, p<.01$; conflict: $\beta=.31, p<.01$ ), the culture difference for the prediction of intimacy with the mother reached only a trend level of significance $(\beta=.18, p<.10)$.

With respect to the prediction of the quality of the relationship with the father, no significant effects of perceived reciprocity occurred in either the Korean or German sample. Thus, the expectation that perceived lack of reciprocity is for German daughters negatively related to the quality of the relationship with the parents, but not for Korean daughters, was only confirmed with respect to the relationship with the mother and only for the perception of the daughters that they give more than they received.

\section{Discussion}

The aims of this study were, first, to detect culture specificities and similarities in the prediction of support by values and relationship quality, and second, to investigate the cultural meaning of reciprocity in support among Korean and German women. Overall, we found several similarities in the two samples. However, culture-specific results were also found, especially with respect to perceived reciprocity.

The exchange of support between the generations is more intensive in Korea than in Germany. Overall, these results support the assumption that in a rather relational-oriented, collectivist culture where strong norms of family obligations prevail (the Koreans in the present study hold higher expectations of filial obligations), the exchange of support in families is higher than in more individualistic cultures where values of independence are more important and may compete with values of the family (the Germans in this study reported higher individualism than the Koreans and a similar degree of collectivism).

\section{The Relation between Values and Norms, Relationship Quality and Support Given by the Daughter}

With respect to the effects of values and norms on the support provided by the daughter, interdependent orientations and filial obligations are the most consistent predictors of certain kinds of support to parents in both cultures. In line with our expectations, interdependence is positively related to financial support given to the parents in the Korean sample and to instrumental support in the German sample. Furthermore, high expectations of an adult child's obligations are positively associated with emotional support given by German adult daughters (the same trend is shown in the Korean sample) and with instrumental support in the German sample. These effects do not differ between the two cultures, except for the effect of interdependence on financial support, which is stronger in the Korean sample. Thus, the similarities between both 
samples rather predominate for these two indicators of support. However, in both cultures the relations between family obligations and support to parents were only moderate.

Contrary to our expectation, Korean daughters' individualism was positively related to instrumental support of parents, and their collectivism was negatively related. The relation of collectivism to support is only observable after controlling for the other values and norms, while the respective bivariate correlation of individualism is also significant and positive in the Korean sample. The more individualistic the Korean adult daughters are, the more likely they are to give instrumental support to their parents. It was also found that the Korean adult daughters who score higher on individualism were more likely to be younger, better educated and with smaller household size (Kim et al., 2005), and so in a better position to provide instrumental support.

The associations between relationship quality and support in the Korean and German sample are quite similar, as expected. Intimacy with mother and father is related to Korean and German adult daughters' provision of emotional support to their parents. Intimacy with parents means that the daughters share their feelings and thoughts with their parents, while emotional support implies that the daughters share their parents' feelings and thoughts. Thus, this result emphasizes the give and take of emotional support in the parent-child relationship in both cultures. In both cultures, admiration (that is the extent of acceptance the adult daughter feels she receives from her mother) only plays a minor role in giving support to parents. For Korean daughters, however, the admiration they receive from their fathers is positively related to the various kinds of support.

Conflict with parents is only relevant for support of parents in the Korean sample (with the exception of the relation between conflict with father and instrumental support, also significant in the German sample). All relations are positive, thus, high conflict is associated with giving more support to parents. Here, the direction of the process of interaction between parents and adult daughters should be further investigated. We hypothesize that this process goes as follows: the more support the daughters provide, the more often they have conflicts with their parents. The preliminary analyses showed that conflict with mother and father is less frequent for Korean daughters than for German daughters. Thus, even though it is important for Korean daughters to keep harmony with parents, the support they give can cause conflicts.

One structural aspect might explain this result: the geographical distance between daughters and parents. In the regression analyses, we controlled for geographical distance because there was a difference between both samples: the distance was higher for Korean daughters. 
Nevertheless, this control variable may not completely control for the potentially higher burdens that are associated with support given from a distance. Furthermore, as compared to the German daughters, the Korean daughters are obliged to support their parents-in-law in addition to supporting to their own parents. This double obligation may be rather difficult and sometimes cause split loyalties, which may spill over into the relationship with the parents. Furthermore, we may assume an interaction effect between conflict and giving support. When support increases the strain and interpersonal conflicts, these conflicts may be regulated, especially in a country with high obligations to the family, by providing more support.

The Korean daughters' relationship quality with their fathers is much more important for the support they give to their parents as compared to the German daughters' relationship quality with their fathers. Significantly stronger effects for the Korean sample occur for the degree of (fathers') admiration on financial support and the effects of conflict on emotional and financial support. Even though the Korean father is a more distant figure for the adult daughter than the German father, he contributes to daughters' provision of support to parents.

\section{The Meaning of Perceived Reciprocity of Intergenerational Exchange of Support}

In line with our expectation that Korean daughters would not tend to experience a balanced give and take as is the case for the German women, the Korean daughters more likely report an imbalance in the exchange as compared to the German adult daughters (in both directions). However, this imbalance is only marginally related to the relationship with mother and father. Korean daughters who perceive that they receive more than they give tend to report less intimacy in interactions with their mother. The pattern for the German daughters is different. The vast majority of them perceive a balance in exchange of support. However, those who feel that they give more than they receive report less intimacy and admiration and more conflicts in the relationship with their mother. This finding implies that German daughters have a less positive relationship with their parents when giving and receiving support is unbalanced. This is in clear contrast to the results from the Korean sample.

Given the Confucian idea of development including the past and the future and the respective continuity of the family across the generations, the Korean daughters need not reciprocate the support they have received from their parents in this specific relationship and with respect to the kind of support. Instead, they can 'pay back' their parents through intensive support of their own children, since their investment in the next generation is seen as paying back their debts (Park and Kim, 2004). Taking into 
account the stronger individualism in the German sample, one might expect that the relationship with the mother suffers from feelings of dependency in the case of those daughters who receive more than they give. However, one can assume that the fact (and maybe the underlying norm) that parents in Germany usually give more to their children than they receive, at least as long as they are in good health, prevents daughters from feeling negatively towards the relationship with their parents. In contrast, giving more than receiving is an unusual situation for adult daughters. In line with another study on German women, this feeling of under-benefiting is associated with felt burdens that are derived from the support given (Schwarz et al., 2005).

Thus, the cultural difference in the meaning of reciprocity is one of the most striking results in the present study. Further analyses should examine whether reciprocity is differentially related to other aspects of the parent-child relationship (Trommsdorff, in press a). For instance, we have seen in a separate study that the willingness to care for the elderly parents is related to Korean and German women's perception and evaluation of reciprocity (Schwarz and Trommsdorff, in prep.).

\section{Caveats and Conclusions}

Several limitations of the present study should be mentioned. Most importantly, the present data are cross-sectional in nature, thus precluding definitive conclusions with regard to causality. Longitudinal data would allow for more substantial inferences concerning the causal path from relationship quality to exchange of support, from exchange of support to perceived reciprocity, and in turn from reciprocity back to relationship quality. Moreover, we can rely here only on the report of the adult daughters. Since the data from the Value of Children Study allow the inclusion of the mother's perspective as well (but only for a smaller sample of 100 mother-daughter dyads), these data will be part of further analyses.

Even though the present sample was quite large, these persons were recruited in regions that cannot necessarily be considered as representative regions in either country. Thus, the results are not necessarily representative of the two countries. However, other results from representative studies in both countries are in line with our study with respect to the amount of support given and received by the adult daughters (e.g. Chung et al., 1998; Kohli and Künemund, 2001). Therefore, this supports the validity of the results of this study. In the present study, we included only one Confucian and one western culture; therefore, we cannot simply generalize our results for other Confucian or western cultures. However, the Value of Children Study includes samples from the People's Republic of China, too. Therefore, further analyses of our data from the cross-cultural 
study on value of children and intergenerational relations will investigate whether the results for Korea are replicated in another Confucian culture (e.g. Schwarz and Trommsdorff, in prep.; Trommsdorff, in press a). These analyses will be used to strengthen the present interpretation of the influence of Confucian and western values on parent-child relationships in different cultures.

Nevertheless, the present study provides insight into similarities and differences in several aspects of the support process between adult daughters and their parents in Korea and Germany. Norms and values with respect to the family and the quality of the relationship play an important role in both cultures for the support daughters provide to their parents. However, the meaning of perceived reciprocity differs in both countries. Thus further studies will have to take into account the culturespecific meaning of parent-child relationships including its consequences for actual behaviour such as mutual support.

\section{Notes}

This research was supported by a grant from the Deutsche Forschungsgemeinschaft (TR 169/9-1-3) to the second author. The project is part of the study 'Value of Children Revisited' (principal investigators: Gisela Trommsdorff, University of Konstanz and Bernhard Nauck, Technical University of Chemnitz, Germany). We are grateful to Holly Bunje for her linguistic support.

1. It is necessary to distinguish between financial and instrumental support since each kind of support requires different resources on the part of the provider and fulfils different needs of the recipient. In the literature of social support, a third kind of support is mentioned: emotional support. Emotional support refers to providing comfort and taking care of concerns (Pierce et al., 1996).

2. We are aware that the construct of individualism/collectivism has also been criticized (e.g. Oyserman et al., 2002).

\section{References}

Aiken, L. S. and West, S. G. (1991) Multiple Regression: Testing and Interpreting Interactions. Newbury Park, CA: Sage.

Alt, C. (1994) Reziprozität von Eltern-Kind-Beziehungen in Mehrgenerationennetzwerken [Reciprocity in the Parent-Child Relationship in Multigenerational Networks], in W. Bien (ed.) Eigeninteresse oder Solidarität. Beziehungen in modernen Mehrgenerationenfamilien, pp. 197-222. Opladen: Leske und Budrich.

Antonucci, T. C. (1985) 'Personal Characteristics, Social Support, and Social Behavior', in R. H. Binstock and E. Shanas (eds) Handbook of Aging and the Social Sciences, pp. 94-128. New York: Van Nostrand Reinhold.

Arnold, F., Bulatao, R. A., Buripakdi, C., Chung, B. J., Fawcett, J. T., Iritani, T., Lee, 
S. J. and Wu, T.-S. (1975) 'The Value of Children: A Cross-National Study', Introduction and Comparative Analysis 1. Honolulu, HI: East-West Population Institute.

Bengtson, V. L. and Roberts, R. E. L. (1991) 'Intergenerational Solidarity in Aging Families: An Example of Formal Theory Construction', Journal of Marriage and the Family 53: 856-70.

BMFSFJ (Bundesministerium Für Familie, Senioren, Frauen Und Jugend) (2003) Die Familie im Spiegel der amtlichen Statistik [The Family in Population Statistics]. Berlin: BMFSFJ.

Buhl, H. M. (2000) 'Biographische Übergänge und Alter als Determinanten der Eltern-Kind-Beziehung im Erwachsenenalter' [Biographical Transitions and Age as Determinants of the Adult Parent-Child Relationship], Zeitschrift für Soziologie der Erziehung und Sozialisation 20: 391-409.

Chan, D. K.-S. (1994) 'Colindex: A Refinement of Three Collectivism Measures', in U. Kim, H. C. Triandis, C. Kagitcibasi, S.-C. Choi and G. Yoon (eds) Individualism and Collectivism: Theory, Method, and Applications, pp. 200-10. Thousand Oaks, CA: Sage.

Chung, K.-H., Cho, A.-J., Oh, Y.-H., Byun, J.-K., Byun, Y.-C. and Moon, H.-S. (1998) The 1998 National Study of the Status of the Elderly and Social Security Need Assessment. Seoul: Korean Social Public Health Research Institute (in Korean).

Furman, W. and Buhrmester, D. (1985) 'Children's Perceptions of the Personal Relationships in their Social Networks', Developmental Psychology 21: 1016-24.

Gouldner, A. W. (1960) 'The Norm of Reciprocity: A Preliminary Statement', American Sociological Review 25: 161-78.

Hofstede, G. (1980) Culture's Consequences: International Differences in Work-Related Values. Beverly Hills, CA: Sage.

Hofstede, G. (2001) Culture's Consequences: Comparing Values, Behaviors, Institutions, and Organizations across Nations, 2nd edn. Thousand Oaks, CA: Sage.

Hong, D. (1998) 'Perception of Emotions and Exchange with Adult Children by Elderly Parents', Korean Journal of Family 36(12): 115-27 (in Korean).

Hwang, K.-K. (1999) 'Filial Piety and Loyalty: Two Types of Social Identification in Confucianism', Asian Journal of Social Psychology 2: 163-83.

Jung, K. and Honig, A. S. (2000) 'Intergenerational Comparisons of Paternal Korean Childrearing Practices and Attitudes', Early Child Development and Care 165: 59-84.

Kim, D.-S., Park, K.-S. and Lee, S.-Y. (2000) 'Parental Support among Middle-Aged Adults and their Parents', Korean Population Studies 23(1): 55-90 (in Korean).

Kim, J.-S. and Kim, Y.-K. (2000) 'Generational Differences of Social Support and Life-Satisfaction', Korean Elderly Research 20(2): 155-68 (in Korean).

Kim, U. (1994) 'Individualism and Collectivism: Conceptual Clarification and Elaboration', in U. Kim, H. C. Triandis, C. Kagitcibasi, S.-C. Choi and G. Yoon (eds) Individualism and Collectivism: Theory, Method, and Applications, pp. 19-40. Thousand Oaks, CA: Sage.

Kim, U. and Choi, S.-H. (1994) 'Individualism, Collectivism and Child Development: A Korean Perspective', in P. Greenfield and R. Cocking (eds) CrossCultural Roots of Minority Child Development, pp. 227-58. Hillsdale, NJ: Lawrence Erlbaum.

Kim, U. and Park, Y.-S. (2000) 'Confucian and Family Values: Their Impact on 
Educational Achievement in Korea', Zeitschrift für Erziehungswissenschaft 3: 229-49.

Kim, U. and Park, Y.-S. (2005) 'Integrated analysis of indigenous psychologies: Comments and extensions of ideas presented by Shams, Jackson, Huang and Kashima', Asian Journal of Social Psychology 8: 75-95.

Kim, U., Park, Y.-S., Kwon, Y. E. and Koo, J. S. (2005) 'Values of children, parent-child relationship, and social change in Korea: Indigenous, psychological, and cultural analysis', Applied Psychology: An International Review 54: 338-54.

Kim, U., Triandis, H. C., Kagitcibasi, C., Choi, S.-C. and Yoon, G. (1994) Individualism and Collectivism: Theory, Method, and Applications. Thousand Oaks, CA: Sage.

Kohli, M. and Künemund, H. (2001) 'Geben und Nehmen. Die Älteren im Generationenverhältnis' [Give and Take: The Elderly in Intergenerational Relations], Zeitschrift für Erziehungswissenschaft 4: 513-28.

Korean Ministry of Public Welfare (2002) Introduction to Social Security Programs for the Elderly. Seoul: Government of Korea (in Korean).

Korean National Statistics Bureau (2001) Annual Statistics. Seoul: Government of Korea (in Korean).

Lauterbach, W. (1995) 'Die gemeinsame Lebenszeit von Familiengenerationen' [The Period of Life that Family Generations Spend Together], Zeitschrift für Soziologie 24: 22-43.

Lee, S. M. (2002) 'The Effect of Socio-Economic Status on Health and Social Support', Korean Elderly Research 22(3): 135-57 (in Korean).

Levitt, M. J. and Guacci, N. (1992) 'Intergenerational Support, Relationship Quality, and Well-Being', Journal of Family Issues 13: 465-81.

Markus, H. R. and Kitayama, S. (1991) 'Culture and the Self: Implications for Cognition, Emotion, and Motivation', Psychological Review 98: 224-53.

Oyserman, D., Coon, H. M. and Kemmelmeier, M. (2002) 'Rethinking Individualism and Collectivism: Evaluation of Theoretical Assumptions and MetaAnalyses', Psychological Bulletin 128: 3-72.

Park, Y.-S. and Kim, U. (2003) 'Parent-Child Relationship, Achievement Motivation, and Academic Achievement of Korean Adolescents: An Indigenous Psychological Analysis', Korean Journal of Youth Studies 10(1): 139-65 (in Korean).

Park, Y.-S. and Kim, U. (2004) Parent-Child Relationship in Korea: Indigenous Psychological Analysis of Self-Concept and Family Role, Seoul, South Korea: Kyoyook Kwahaksa (in Korean).

Park, Y.-S., Kim, U. and Min, B.-K. (2002) ‘The Influence of Parental Social Support on Self-Efficacy and Life-Satisfaction: A Longitudinal Analysis of Korean Adolescents', Korean Journal of Educational Psychology 16(2): 63-92 (in Korean).

Pierce, G. R., Sarason, B. R., Sarason, I. G., Joseph, H. J. and Henderson, C. A. (1996) 'Conceptualizing and Assessing Social Support in the Context of the Family', in G. R. Pierce, B. R. Sarason and I. G. Sarason (eds) Handbook of Social Support and the Family, pp. 3-24. New York: Plenum Press.

Rook, K. S. (1987) 'Reciprocity of Social Exchange and Social Satisfaction among Older Women', Journal of Personality and Social Psychology 52: 145-54.

Schneewind, K. A. and Ruppert, S. (1995) Familien gestern und heute: ein 
Generationenvergleich über 16 Jahre [Families Yesterday and Today: A Comparison of Generations across 16 Years]. Munich: Quintessenz.

Schwartz, S. H. and Bilsky, W. (1990) 'Toward a Theory of the Universal Content and Structure of Values: Extensions and Cross-Cultural Replications', Journal of Personality and Social Psychology 58: 878-91.

Schwarz, B. (in press) 'Adult Daughters' Family Structure and the Association between Reciprocity and Relationship Quality', Journal of Family Issues.

Schwarz, B. and Trommsdorff, G. (in prep.) 'Reciprocity in Intergenerational Support: A Comparison of Korean, Chinese, and German Adult Daughters', manuscript (in prep.).

Schwarz, B., Trommsdorff, G., Albert, I. and Mayer, B. (2005) 'Adult Parent-Child Relationship: Relationship Quality, Support, and Reciprocity', Applied Psychology: An International Review 54(3): 401-22.

Silverstein, M., Conroy, S. J., Wang, H., Giarrusso, R. and Bengtson, V. L. (2002) 'Reciprocity in Parent-Child Relations over the Adult Life Course', Journal of Gerontology 57B: 3-13.

Singelis, T. M. (1994) 'The Measurement of Independent and Interdependent SelfConstruals', Personality and Social Psychology Bulletin 20: 580-91.

Sung, K.-T. (1995) 'Measures and Dimensions of Filial Piety in Korea', The Gerontologist 35: 240-7.

Sung, K.-T. (1998) 'Filial Piety in Modern Times: Timely Adaptation and Practice Patterns', Australasian Journal of Ageing 17: 88-92.

Szydlik, M. (2000) Lebenslange Solidarität? Generationenbeziehungen zwischen erwachsenen Kindern und Eltern [Lifelong Solidarity? Intergenerational Relations between Adult Children and Parents]. Opladen: Leske und Budrich.

Szydlik, M. (2002) 'Wenn sich Generationen auseinanderleben [When Generations Drift Apart]', Zeitschrift für Soziologie der Erziehung und Sozialisation 4: 362-73.

Trommsdorff, G. (2001) 'Value of Children and Intergenerational Relations: A Cross-Cultural Psychological Study'; at: www.uni-konstanz.de/FuF/SozWiss/ fg-psy/ag-entw/english

Trommsdorff, G. (in press a) 'Parent-child relations over the life-span: A crosscultural perspective', in K. H. Rubin and O. B. Chung (eds) Parenting beliefs, behaviors, and parent-child relations in cross-cultural perspective. New York: Psychology Press.

Trommsdorff, G. (in press b) 'Intergenerational Relations and Cultural Transmission', in U. Schönpflug (ed.) Perspectives on Cultural Transmission. Oxford: Oxford University Press.

Trommsdorff, G. and Nauck, B. (eds) (2005) The value of children in cross-cultural perspective. Case studies from eight societies. Lenerich, Germany: Pabst Science.

Uhlenberg, P. (1995) 'Commentary: Demographic Influence on Intergenerational Relationship', in V. L. Bengtson, K. W. Schaie and L. M. Burton (eds) Adult Intergenerational Relations: Effects of Societal Change, pp. 19-25. New York: Springer.

United Nations Population Division (2004) 'World Population Prospects: The 2002

Revision and World Urbanization Prospects: The 2001 Revision'; at: esa.un.org/unpp

Won, Y.-H. (2002) 'Support of the Elderly', in M. S. Kim et al. (eds) Family and Sociological Understanding. Seoul: Hakjisa (in Korean). 
Beate Schwarz is assistant professor at the University of Basle, Switzerland. Her main research interests focus on social relationships and problem behaviour in adolescence, children and adolescents in divorced and stepfamilies, the parent-child relationship in adulthood and cross-cultural psychology.

Address: University of Basle, Department of Psychology, Missionsstr 62a, 4055 Basle, Switzerland. [email: beate.schwarz@unibas.ch]

Gisela Trommsdorff holds the Chair for Developmental and Cross-Cultural Psychology at the University of Konstanz, Germany (since 1987). Her research interests cover cross-cultural psychology, future orientation, life span development, intergenerational relationships, social change, subjective developmental theories, motivation and intentionality.

Address: University of Konstanz, Department of Psychology, Box D 14, 78457 Konstanz, Germany. [email: G.Trommsdorff@uni-konstanz.de]

Uichol Kim is Inha Fellow Professor at Inha University, South Korea. He has taught at the University of Hawaii at Manoa, The University of Tokyo and Chung-Ang University, South Korea. He has published over 100 articles and 12 books on the topics of indigenous psychology, individualism and collectivism, family and the parent-child relationship, educational attainment, organizational culture, political culture, democracy and human rights.

Address: Inha Fellow Professor, College of Business Administration, Inha University, 253 Yonghyun-dong, Nam-gu, Incheon, 402-751, South Korea. [email: uicholk@yahoo.com]

Young-shin Park is a professor at the Department of Education at Inha University, Incheon, South Korea. She specializes in the area of educational psychology and has written over 80 articles and 10 books on the parent-child relationship, academic achievement, achievement, self-efficacy, delinquent behaviour, school violence, trust, quality of life and indigenous psychology.

Address: Department of Education, 253, Yonghyun-dong, Nam-gu, Incheon, 402-751, South Korea. [email: yspark@inha.ac.kr] 